\title{
Comunicação em saúde: Habermas e Lévinas no consultório
}

\author{
Communication in healthcare: Habermas and \\ Lévinas at the medical office
}

Carlos Eduardo Pomplio*

Resumo: A partir da apresentação de três casos clínicos, o autor se lança a uma crítica à matriz teórica da Medicina Narrativa e do que tem sido conhecido como Humanidades Médicas. Pretende-se mostrar que tornar narrativas de pacientes um objeto privilegiado de estudo dos profissionais da saúde e utilizar de métodos quantitativos para medir sua eficiência ou, por fim, considerá-las mero instrumento para se atingir metas terapêuticas ou mesmo acolhimento, é empobrecer o debate no campo do que Hydén e Mishler chamaram de "Linguagem e Medicina". Por outro lado, submeter o encontro clínico à exclusividade de uma análise linguística é insuficiente, se considerarmos a ciência biomédica que o legitima. Uma (ainda) utópica teoria da comunicação em saúde teria que, para atender a tais demandas, dar conta de todas as aporias e contingências da linguagem que o encontro clínico proporciona e, além disso, acomodar a potência colossal representada pelo discurso científico na sociedade moderna. Tais questionamentos nos remetem às relações entre epistemologia e ética que estão, desde sempre, no âmago da medicina. Trata-se, portanto, de procurar especificamente por linhas de pensamento que sejam estruturadas, ou bem como teorias da linguagem que terminam por desaguar em uma ética do encontro, ou, bem contrariamente, como filosofias que, a partir da interação ética entre indivíduos e de uma matriz linguística dela derivada, compõem uma teoria do conhecimento.

Palavras-chave: medicina, linguagem, medicina narrativa, Habermas, Lévinas

\footnotetext{
* Clínico Geral e Médico Coordenador Clínico do Setor de Saúde Suplementar do Instituto Central do HCFMUSP. Coordenador do GENAM (Grupo de Estudos em Narrativa e Medicina da Universidade de São Paulo).
} 


\begin{abstract}
From the presentation of three clinical cases, this article aims to show that discursive patterns and meanings built throughout the clinical practice comprise a wide range of forms and events, and poses a critique of Narrative Medicine and Medical Humanities theoretical frameworks. The intention is to demonstrate that determining narratives as a health professionals' privileged object of study, using quantitative methods to measure their efficiency or even considering them mere instruments to achieving therapeutic goals or empathy is to impoverish the debate in the field that Hyden and Mishler have called "Language and Medicine". Also, the conduction of clinical encounters exclusively under a linguistic analysis is insufficient, considering the biomedical science that grounds them. These questions refer to the relationship between epistemology and ethics, which always permeated the core of medicine. In this sense, Jürgen Habermas' and Emanuel Lévinas' philosophies (the first, starting from a theory of language build up an ethics of the encounter, and the second, in opposite, from the ethical interaction among people proposing a theory of knowledge) can offer a more solid basis for the comprehension of the clinical encounter in its technical and discursive aspects, towards a (still) utopian theory of communication in health.
\end{abstract}

Keywords: medicine, language, narrative medicine, Habermas, Lévinas 
e, por um lado, podemos afirmar - quase consensualmente - que a medicina é uma prática profundamente embasada em conhecimentos científicos, por outro - já sem a mesma unanimidade -, assumiremos aqui que sua essência é o encontro clínico ${ }^{1}$ (PELLEGRINO \& THOMASMA, 1981; SVENAEUS, 2001). No encontro clínico, caracterizado como a relação inter-humana entre o(a) paciente (eventuais acompanhantes inclusos) e seu médico(a)², estão em jogo, a um só tempo, o estado-da-arte da ciência biomédica, valores ético-morais e o ambiente sociocultural no interior do qual ele transcorre, de maneira tal que seus coparticipantes ao estabelecer "um nexo de escolhas e prioridades" muito particular (PELLEGRINO \& THOMASMA, 1981) - nexo este, cujo horizonte decisório tem como norte o télos da restituição de um estado de bem-estar indissociável do conceito vigente de saúde -, desvelam, hic et nunc, a constituição própria da medicina.

Tal opção permite tomar a prática médica sob o ponto de vista da intersubjetividade e, assim, explorar conceitos fundamentais que de outro modo permaneceriam ocultos caso olhados exclusivamente sob o ponto de vista analítico do processo. As ricas análises fenomenológicas das doenças (SVENAEUS, 2001; TOOMBS, 2001; WARSOP, 2011), a hermenêutica aplicada às práticas de saúde (AYRES, 2005; 2007; GADAMER, 1996), a percepção normativa e suas consequências, inclusive políticas, dos conceitos de normal e patológico (CANGUILHEM, 1990; SAFATLE, 2011), e mesmo a relação que comportamentos como a empatia podem ter com conceitos fenomenológicos (RATCLIFFE, 2006), são alguns poucos exemplos de interessantes aquisições conceituais. Entre as vantagens da abordagem intersubjetiva do encontro clínico está o fato de que ela permite avaliar a linguagem sob um ponto de vista diferente daquele lógico-formal (ou semântico-formal) mais adequado ao discurso da ciência biomédica que o embasa (ver, por exemplo SADEGH-ZADEH, 2015). Considerando a importância das análises lógico-formais da linguagem, estaremos mais interessados no cará-

\footnotetext{
1 Há vários tipos de encontros clínicos que, em maior ou menor grau, podem abrigar o tipo de relação a qual estamos nos referindo, o que não deixa de ser problemático. Ver comentário crítico sobre o assunto em "The discourse of medicine", em (ATKINSON, 1988)

2 "Todos os profissionais da saúde entram, em algum grau, nesse nexo relacional; dessa forma incluímos todos os profissionais da saúde em nossa avaliação. Utilizamos a medicina e a relação médico-paciente como paradigma devido a seus precedentes morais, legais e históricos" (PELLEGRINO \& THOMASMA, 1981, p. 5). Esperamos, como os autores, que todos os profissionais da saúde, e não apenas os médicos, se reconheçam na descrição do encontro clínico que seguirá.
} 
ter dialógico (ou pragmático) que se instaura numa interação clínica verdadeira e, para isso, utilizaremos as análises de autores mais ligados às vertentes linguística e ética do estudo da intersubjetividade e suas relações com a linguagem.

Tendo isso como base, apresentamos, a seguir, três relatos de encontros clínicos em que habilidades médicas são requisitadas em situações-limite. Nesses três relatos, um exame altamente especializado (tomografia computadorizada de crânio) é solicitado. Contudo, não é exatamente o exame que permite o diagnóstico potencialmente salvador da vida dos pacientes. Ele parece ter sido feito muito mais pelo julgamento clínico dos profissionais que, por intermédio de uma interpretação dos signos e manipulação de dados em três diferentes níveis de intimidade com uma (na ausência de termo mais adequado) "relação linguística", tiveram acesso a "verdades" que os falantes depreenderam por via não necessariamente - ou não apenas - lógico-formal, que se relacionavam ao caráter pragmático/performativo de toda comunicação humana.

\section{Caso 1}

Um rapaz de 20 anos de idade, usuário de drogas inalatórias e álcool, sofreu acidente motociclístico no qual fraturou o fêmur direito. Após avaliação e compensação clínica, foi realizada a fixação cirúrgica da fratura, sem maiores intercorrências. No $4^{\circ}$ dia após a cirurgia, o paciente apresentou sonolência alternada com períodos de agitação intensa, além de desconforto respiratório. $O$ médico plantonista solicitou uma tomografia de crânio que resultou normal, pedindo a imediata transferência do paciente à unidade de terapia intensiva (UTI) com a hipótese diagnóstica de abstinência a drogas ou ao álcool. O médico da UTI ouviu o relato pessoa ${ }^{3}$ do outro profissional com atenção, aproximou-se do paciente e, com o polegar direito, tracionou delicadamente a pálpebra inferior de seu olho esquerdo. Da avermelhada conjuntiva palpebral, assim exposta, surgiram duas petéquias, pontos de hemorragia cutânea, com o que o diagnóstico de embolia gordurosa foi firmado.

3 No jargão médico, trata-se da passagem do caso, momento no qual a responsabilidade pelo paciente é transferida ou, ao menos, compartilhada a partir de então. 


\section{Caso 2}

Uma mulher de 44 anos, com história crônica de enxaqueca e depressão, procurou sua médica devido à nova crise de dor de cabeça. A dor começara há dois dias com episódio agudo e muito intenso, acompanhada de náuseas e vômitos, além de "certo embaralhamento das ideias" (sic). No momento da consulta, referia estar um pouco melhor com as medicações que estava habituada a tomar. Vinha apenas para renovar receitas de algumas medicações controladas e "ver se estava tudo bem". Após um exame clínico sem maiores alterações, enquanto a médica prescrevia as medicações solicitadas, a paciente fez a seguinte observação, no mesmo tom de lamentação de sempre: "Essa dor de cabeça foi a pior dor de cabeça que eu já senti na vida. " A médica, ao ouvir tal queixa, interrompeu a prescrição dos medicamentos e, ao invés de dispensá-la, encaminhou-a imediatamente ao setor de emergência com um relatório sugerindo a realização de uma tomografia de crânio. A paciente alegou que não era necessário, mas, relutantemente, acabou concordando com a conduta. $O$ exame foi realizado e $O$ diagnóstico de hemorragia subaracnoide foi confirmado.

\section{Caso 3}

O telefone celular de um clínico geral tocou na manhã de segunda-feira durante sua atribulada visita matinal aos pacientes do hospital-escola onde trabaIhava todos os dias. Era a mãe de uma garota de 13 anos cuja família era de longa data conhecida. Ela Ihe contou, preocupada, que sua filha tinha apresentado diarreia e estava se comportando estranhamente. O médico solicitou à mãe que a trouxesse à sua presença imediatamente, deixando-a ainda mais apreensiva. Após examiná-la, ele solicitou uma tomografia de crânio que resultou normal, indicando, então, o exame do liquor que confirmou o diagnóstico de meningite meningocócica ${ }^{4}$.

No Caso 1, o médico da UTI utiliza os fatos da história do paciente e os integra a dados epidemiológicos e conceitos fisiopatológicos para conceber a hipótese

4 Relato de caso modificado de (GREENHALGH, 1999). 
diagnóstica da síndrome da embolia gordurosa. Tal quadro ocorre em 1-5\% dos pacientes que sofrem fraturas de ossos longos e é, provavelmente, devido à liberação de componentes da medula óssea (tecido que é muito rico em lípides) diretamente na circulação sanguínea. A história e o quadro clínico do paciente eram sugestivas, mas também eram compatíveis com a abstinência devido ao histórico de consumo de drogas lícitas e ilícitas. Faltava a confirmação cabal que o médico foi buscar no exame das pálpebras do paciente. As petéquias estão presentes nesse contexto em até $50 \%$ dos casos e, quando somadas ao quadro clínico, praticamente confirmam o diagnóstico. A discussão dos detalhes probabilísticos ${ }^{5}$ envolvidos nesse raciocínio estão fora do propósito deste ensaio; contudo, é importante frisar aqui que estamos em terreno bastante familiar à prática médica regular. Apesar da precisão do diagnóstico, não há recurso a um saber externo à ciência biomédica. Note-se, entretanto, que, a despeito da transmissão enviesada das informações em relação ao consumo de drogas do paciente pelo primeiro médico, o segundo soube como reconfigurar a história de modo que um novo e possível diagnóstico surgisse.

No Caso 2, a médica ouve pacientemente as mesmas e frequentes queixas de uma paciente já sua conhecida. Entretanto, durante a consulta, que transcorria tal como as outras, a paciente cita uma frase que faz com que a médica mudasse totalmente sua concepção do caso: "a pior dor de cabeça da minha vida" é título de capítulos de livros e artigos em revistas científicas de medicina em várias línguas $^{6}$. Não é difícil imaginar que essa mesma declaração pode ser feita em diferentes contextos (uma conversa entre duas amigas, por exemplo) sem, contudo, dispor da mesma força que foi capaz de mudar radicalmente a conduta da médica frente à queixa da paciente. Nesse caso, é importante ressaltar o fato de uma frase proferida em determinado contexto disparar um comportamento técnico altamente especializado, enraizado em conceitos fisiopatológicos e epidemiológicos consistentes e, ao final, poder evitar complicações neurológicas graves, se

5 Referimo-nos aos conceitos de probabilidade pré-teste, sensibilidade e especificidade, aos quais todo médico familiariza-se e aprende a raciocinar já durante a graduação.

6 Ver, por exemplo, em inglês: Rae-Grant, A. Weiner and Levitt's Neurology. 8th Ed. p.94; em português: Current - Essência da Medicina (Lange). Ed. Lawrence M. Tierney Jr.; Sanjay Saint; Mary A. Whooley. $4^{a}$ Edição, p. 351; em espanhol: o artigo de revisão do portal médico Medline Plus https://www.nlm.nih.gov/medlineplus/spanish/ency/article/001414.htm (consultado em 10/11/2015), entre muitos outros. 
não a própria morte de alguém. Com a apresentação desse caso, gostaríamos de chamar a atenção à possibilidade de que uma sentença verbal signifique um sangramento intracraniano.

O Caso 3 é algo mais sutil. Ele descreve um médico de família que ouve as queixas de uma mãe apreensiva com o mal-estar de sua filha. Queixas de diarreia e desconforto são extremamente inespecíficas e podem corresponder a uma enorme lista de doenças, em especial, em seus períodos iniciais (pródromos). Quando, no relato original, perguntaram ao médico a razão de ter solicitado a presença imediata da paciente para sua avaliação, mesmo tendo em vista apenas queixas inespecíficas, ele respondeu que foi devido à palavra "estranhamente". Como explica Greenhalgh:

Uma interpretação da ação deste médico é que ele subconscientemente comparou o "roteiro" de dezenas de milhares de "roteiros de doenças" de crianças ao longo dos anos que vieram a se tornar (ou foram diagnosticadas) agudamente doentes e decidiu que tal roteiro não se encaixava no formato "nada com que se preocupar". A palavra "estranhamente" é raramente utilizada pelos pais para descrever manifestações não específicas de moléstias infantis (compare expressões familiares como "ela está sem cor", "abatida", "caída", "fraca", todas ocupando um espaço semântico muito diferente de "estranha"). Pode ter sido esta simples palavra que alertou o médico da seriedade do caso (GREENHALGH, 1999, p. 324)7.

Mas dizer isso é ainda dizer pouco. Onde está a ligação, neste caso, entre o advérbio "estranhamente" aplicado de um modo não costumeiro e o impulso de querer examinar a criança imediatamente? Não se trata, como no Caso 1, de uma reconfiguração do encadeamento lógico dos fatos. Também não parece ser, como no Caso 2, uma situação na qual uma sentença dispara um comportamento técnico cientificamente embasado. $O$ médico não tinha nada em mente quando solicitou a presença da menina à mãe. A correspondência entre discurso e ação aqui é bem mais tênue e distante. Qual operador mental seria o responsável por essa correlação? Que tipo de vínculo existe entre o abstrato uso corrente de uma palavra e a intuição do diagnóstico? Antes de nos debruçarmos sobre

7 As traduções dos originais são sempre de responsabilidade do autor salvo quando especificado. 
essas questões, discutiremos alguns aspectos históricos e também algumas críticas ao modelo vigente de análise da linguagem envolvida no encontro clínico.

\section{Medicina narrativa - breve escorço histórico, necessariamente incompleto ${ }^{8}$}

A análise da linguagem envolvida no encontro clínico tem sido dominada pelo que se convencionou chamar recentemente de Medicina Narrativa. A palavra "narrativa" provém do latim narratio que, por sua vez, se origina do particípio passado de narrare que significa "contar, relatar, recontar, explicar". Literalmente, passa a ideia de "tornar algo conhecido", sentido conferido pelo radical proto-indo-europeu gnâ (raiz *gno-) que significa "conhecer, saber"9. Denomina-se Medicina Narrativa a corrente teórica bioética de orientação narrativista que se articula com as práticas de Saúde surgida especialmente no mundo anglófono (MCCARTHY, 2003) ${ }^{10}$. A Medicina Narrativa surge precocemente como parte da Narratologia - campo transdisciplinar de antropólogos, filósofos, filólogos, psicólogos cognitivos, historiadores e médicos, entre outros que têm em comum a percepção de que narrativas produzidas em contextos específicos - no nosso caso, clínicos - poderiam tematizar algo além de informações meramente técnicas e de uso eminentemente operacional. Uma das primeiras manifestações nesse sentido é proveniente de Alasdair Maclntyre em 1981 (MACINTYRE, 2007) em sua obra sobre filosofia moral After Virtue:

É porque todos nós vivenciamos narrativas em nossas vidas e porque entendemos nossas próprias vidas em termos narrativos que a forma narrativa é adequada à

8 Para uma visão menos dirigida e mais abrangente sobre o assunto Cf. (MISHLER, 2005).

9 Não deixa de ser interessante notar que a palavra grega gnósis ( $\gamma v \tilde{\omega} \sigma \iota \varsigma)$, a inglesa know e "narrativa" têm a mesma raiz. Fonte: Verbete know do Online Etymology Dictionary http://www. etymonline.com (consultado em 13/11/2015).

10 Grosso modo, seriam ao menos duas as linhas teóricas principais nas discussões bioéticas atuais: o principialismo e a ética narrativa. Segundo Maccarthy "[...] o principialismo adota uma abordagem sistemática frente às decisões éticas e pretende submeter nossas conviç̧ões morais a uma profunda e consistente abordagem unificada. Por outro lado, a ética narrativa leva em conta a história de vida individual em sua singularidade irrepetível como ponto de partida, e resiste à tendência de generalizar, mesmo com o risco de ser acusada de inadequação teórica" (MCCARTHY, 2003). 
compreensão da ação dos outros. Estórias são vividas antes de serem contadas (...) (MACINTYRE, 2007, p. 212).

A partir daí, começam a surgir trabalhos de psicólogos como Elliot Mishler, de 1984 (MISHLER, 1984), e de médicos como Howard Brody, em 1987 (confessamente inspirada na declaração de Maclntyre), e Arthur Kleinman que abordam, cada um a seu modo, os aspectos sociais, psicológicos e ético-morais das doenças por meio da análise de transcrições de consultas médicas. Manifestações esparsas a respeito do tema foram reunidas em 1998 pelos britânicos Trisha Greenhalgh e Brian Hurwitz no livro Narrative Based Medicine (GREENHALGH; HURWITZ, 1998) e logo após, em artigos no British Medical Journal (GREENHALGH, 1999; GREENHALGH; HURWITZ, 1999). Neles, os autores questionam as limitações da objetividade produzidas pela extrapolação dos limites sugeridos da prática conhecida como Medicina Baseada em Evidências (Evidence-Based Medicine - EBM). Basicamente, ao considerar o médico como um cientista em busca de hipóteses para o diagnóstico de seus pacientes, a EBM assume que a tomada de decisão clínica "segue um protocolo indistinguível da investigação científica" (GREENHALGH, 1999). Sugere-se, nesses textos, que não é preciso substituir uma abordagem por outra, mas trabalhar com uma integração de saberes que levem em conta algo que não está nos estudos "randomizados" duplo-cegos e placebos controlados, paradigmas do fato médico aplicável, nem tampouco nos dados epidemiológicos das doenças, fontes do raciocínio probabilístico. Em 2001, Rita Charon publica um artigo no importante Journal of American Medical Association (CHARON, 2001) sobre a relação médico-paciente e como a medicina narrativa poderia influenciá-la positivamente. Alguns anos depois, ela lança o livro Narrative Medicine (CHARON, 2006), fruto de sua atividade no grupo de estudos de narrativa em medicina da Columbia University (EUA), no qual define o campo que dá título à obra como "a medicina praticada com competência narrativa para reconhecer, absorver, interpretar e ser movido pelas estórias de enfermidades" (CHARON, 2006). Coincidentemente com o decréscimo progressivo do entusiasmo pelo modelo de racionalidade proposto pela EBM (CRONJE; FULLAN, 2003; POMPILIO, 2006; GUYATT, 2008; TOBIN, 2008a, b; GREENHALGH et al., 2014), Charon e Wyer criam, na Columbia University um grupo de estudos denominado Narrative Evidence Based Medicine, cuja proposta era 
aprimorar a prática da EBM (CHARON; WYER; NEBM Working Group, 2008). Na palavra dos autores:

Estamos observando que as três tensões fundamentais sobre os quais se encontra a medicina conhecido/desconhecido, universal/particular, corpo/self se refletem nos três círculos de EBM. A evidência clínica examina o conhecido e o desconhecido. O contexto clínico integra o universal e o particular. Os valores do paciente dialogam com o corpo e o self. Em virtude da sua capacidade de reconhecer plenamente tais tensões, a medicina narrativa pode emprestar [lend] à medicina baseada em evidência métodos para que ela considere [respect] os seus três círculos de atenção. Não é por escassez de vontade, mas por escassez de métodos que ainda falta à EBM contemplar os três círculos. Com os métodos da medicina narrativa, a EBM poderá realmente cumprir todas as suas promessas (CHARON; WYER; NEBM Working Group, 2008, p. 297).

Na mesma linha, Meisel et al. (MEISEL; KARLAWISH, 2011) assumem que narrativas de pacientes têm duas aplicações principais: em primeiro lugar, podem traduzir, em linguagem acessível ao público leigo, evidências clínicas significativas. Em segundo, têm o poder de contrabalançar a força de narrativas contrárias aos achados científicos com grande grau de persuasão. Em 2013, Hurwitz e Charon coordenaram o primeiro simpósio sobre o assunto no King's College, em Londres, intitulado "A Narrative Future for the Health Care" (HURWITZ; CHARON, 2013). No mesmo ano, defenderíamos, no âmbito brasileiro, "a possibilidade e a necessidade de um estudo sério e teoricamente aparelhado, da prática médica enquanto produtora de narrativas de vida e de morte", enfatizando que "não ouvir o doente na especificidade de suas narrativas pode, sim, levar à morte - 'desenlace' que [...] cerra para sempre a boca de quem conta" (CARELLI; POMPILIO, 2013).

\section{Críticas ao modelo}

Os estudos de linguagem em medicina ganharam força na esteira de um movimento de "humanização" da prática médica e na valoração do que se conven- 
cionou chamar de humanidades médicas ${ }^{11}$. Tal fato se reveste de importância se pensarmos que as respostas à questão "o que é ser humano?" não são homogêneas, podendo mesmo ser antagônicas em vários aspectos (FOUCAULT, [1966] 1999; SAFATLE, 2012, a partir do capítulo VII, p. 217). Nesse sentido, cabe perguntar que tipo de humanização se busca e que tipo de humanidade a medicina perdeu para que, se for o caso, possamos reavê-la. Sobre isso, Jeffrey Bishop argumenta que se

Nós precisamos de humanidades na medicina porque em algum sentido as humanidades humanizarão novamente a medicina. Em outras palavras, vamos dar à medicina e aos estudantes de medicina uma dose de humanidades de modo que a medicina possa se tornar (uma vez mais?) humanística (BISHOP, 2007, p. 16).

E conclui, ironicamente, que "[p]ara a medicina e para as humanidades médicas, o homem é o Homo humanus" (BISHOP, 2007, p. 16). Bishop ataca, em especial, uma passagem do artigo supracitado de Charon onde ela diz

Somando-se às evidências iniciais da utilidade de práticas narrativas, estudos etnográficos rigorosos e de desfecho usando amostras de tamanho adequado e controles têm sido realizados para verificar a influência sobre os estudantes, médicos e pacientes das práticas narrativas. Paralelamente a tais resultados de pesquisa estão os esforços acadêmicos para descobrir os mecanismos básicos, caminhos intermediários e as consequências das práticas narrativas que abastecem a "ciência básica" de fundamentos teóricos e modelos conceituais para essas novas conquistas (CHARON, 2001, p. 297).

\footnotetext{
11 Duas das mais importantes revistas especializadas sobre o tema são o Medical Humanities, pertencente ao grupo editorial do British Medical Journal, lançado no ano 2000. V. http:// mh.bmj.com/site/about/ (acessado em 16/11/2015), e o atualmente chamado Journal of Medical Humanities do grupo Springer, que já se chamou, retrospectivamente, The journal of medical humanities and bioethics, The journal of bioethics e Bioethics quarterly, na década de 80, em clara mudança de concepção.
} 
Em outras palavras, Charon quer demonstrar a importância das humanidades por meio de metodologia científica ${ }^{12}$. Ao reviver o debate que marcou o século XIX, Charon não só não resolve o problema, como põe em evidência a instrumentalidade da prática que divulga, qual seja, a ideia de que para humanizar a medicina deve-se ter na base o aparelhamento humanístico com fins de resultados técnicos. Isso é o exemplo do que o filósofo alemão Jürgen Habermas chama de ação racional teleológica (HABERMAS, [1968] 2006). O problema disso, segundo Habermas é que

O homem não só pode já, enquanto Homo faber, objetivar-se integralmente pela primeira vez e enfrentar as realizações autonomizadas nos seus produtos, mas pode igualmente, enquanto Homo fabricatus, integrar-se nos seus dispositivos técnicos, se conseguir reproduzir a estrutura da ação racional teleológica no campo dos sistemas sociais. (HABERMAS, 2006, p.75).

Se entendermos as práticas de saúde como parte do que Habermas chama de sistemas sociais, e a medicina como um dos exemplos de dispositivo técnico, entenderemos que o Homo humanus de Bishop é uma tentativa de antídoto ao Homo fabricatus, incômodo e desidratado existencialmente. Mas, ao contrário de curar a "doença", o Homo humanus é um simples paliativo, opiáceo alucinógeno, que apenas posterga o enfrentamento do problema. Bishop se posta firmemente contra esse uso instrumental das humanidades ao dizer que "[c]ertamente há mais na importância educacional das humanidades médicas do que a simples demonstração de um efeito causado pela exposição [dos estudantes] a disciplinas humanísticas" (BISHOP, 2007, p. 23). E completa:

\footnotetext{
12 Não poderíamos perder a oportunidade aqui de notar que nem mesmo os fundadores da Medicina Baseada em Evidências conseguiram provar seu conceito pelo método por eles mesmos preconizado. De acordo com Brian Haynes: "Nós não temos estudos convincentes que demonstrem que pacientes cujos clínicos praticam a EBM vão melhor que aqueles cujos clínicos não a praticam: ninguém fez um estudo randomizado controlado de EBM com os desfechos dos pacientes como medida de sucesso". (HAYNES, 2002).
} 
As humanidades médicas devem também resistir a se transformarem em compensações eloquentes para os biopsicologismos ${ }^{13}$ de nossos dias; devem resistir até mesmo a se transformarem em uma medicina bionarrativista, uma bionarratologia, um bionarrativismo". (BISHOP, 2007, p. 23).

Talvez seja essa a razão de uma tendência, notada por alguns autores, em direção à valoração excessiva (quase uma celebração romântica) das narrativas de estados enfermos (ATKINSON, 2009). A própria história narrada se tornaria assim o fim último do processo narrativo permitindo prescindir de análises mais aprofundadas. Ao médico caberia "apenas" adquirir habilidades para ouvir, "absorver, interpretar e ser movido" por tais narrativas, sendo esse objetivo já em-si plenamente justificado. A riqueza das histórias dos pacientes, entretanto, não parece esgotar-se apenas no advento das narrativas.

\section{Por uma teoria da comunicação em saúde}

Tentamos, por meio de exemplos modificados da prática médica, mostrar que a linguagem envolvida no encontro clínico tem um alcance maior do que a simples coleta de dados relevantes ou do acolhimento concedido pela escuta atenta dos padecimentos de pessoas em estado enfermo. No Caso 1 , uma reconfiguração dos dados só foi possível após a narrativa do primeiro médico que, de certa forma, pré-organizou uma sequência temporal de eventos de modo que o segundo médico pôde reorganizá-las e fazer o diagnóstico. No Caso 2, uma frase dita num contexto adequado conectou uma ação racional a um evento neurovascular potencialmente letal. A maneira não habitual de descrever uma situação clínica, o uso fora das "regras do jogo" de uma única palavra, motivou o médico a solicitar a presença imediata da paciente no Caso 3, o que culminou com o diagnóstico de meningite. Tais casos sugerem algo na comunicação entre médicos e pacientes que talvez se beneficiem de explorações teóricas mais

13 Bishop dialoga aqui com o modelo biopsicossocial de Saúde proposto por George Engel em 1977 (ENGEL, 1977) e citado por Charon como exemplo de conhecimento abarcado pela medicina narrativa, mas não pela medicina baseada em evidências. 
robustas; se esse ensaio puder motivá-las, ele já terá cumprido sua principal incumbência.

Um exemplo desse tipo de análise é a ideia de vozes, normativas e concorrentes, introduzida por Elliot Mishler (MISHLER, 1984), em um dos trabalhos pioneiros sobre narrativas em medicina. Ele se refere a uma voz da medicina e outra voz do mundo da vida (MISHLER, 1984). "A voz da prática médica é descrita em termos de um discurso descontextualizado e impessoal", observa um comentador (ATKINSON, 2009, §2.4), "enquanto a voz do mundo da vida é constituída pelo que é mundano, pessoal e experiencial" (Ibid.). Nem sempre quem profere a voz da medicina é o médico, assim como nem sempre é a voz do mundo da vida proveniente do paciente. Mishler chama a atenção para a assimetria moral poderosa da oposição entre as duas, e também para as interrupções entre as vozes, caracterizando momentos de ruptura importantes na construção de significados.

Analisando depoimentos de uma paciente à sua médica-residente e desta para seu médico-tutor, Carelli et al. (CARELLI et al., 2013) chegam a conclusão semelhante, mas reúnem as diferentes vozes de Mishler em um tipo novo de narrador dito clivado ou "impuro"14. Além disso, ao submeter os discursos à tripartição do conceito aristotélico de mímesis como proposto por Ricoeur (RICOEUR, 2010), esses autores sugerem que a produção de discursos configurados por pacientes e profissionais da saúde sobre eles(as) em contextos clínicos tem "um poder mais radical de referência a aspectos de nosso ser-no-mundo que não podem ser ditos de maneira direta" (RICOEUR, 2010, p. 136), ou seja, que essas (re)configurações narrativas possuem um alcance ontológico e, portanto, reconstrutivo - trazendo à tona toda a densidade existencial que tais expressões têm na atribuição de sentidos (CARELLI, 2013).

Levando-se em consideração tais aspectos, tornar a narrativa do paciente o fulcro principal da atenção dos profissionais da saúde é empobrecer o debate

14 Para Mishler, "alguns discursos são fechados e reafirmam uma única ordem normativa; outros incluem diferentes vozes, cada uma das quais podem interromper a outra, conduzindo assim à possibilidade de uma nova ordem" (MISHLER, 1990). Para Carelli et al. "[...] tal observação nos permite postular um tipo distinto de narrador [...] original e característico do gênero do discurso que convencionamos chamar de consulta médica e que denominaremos de narrador clivado ou impuro: quando duas (ou mais) 'inteligências' dividem as funções implicadas no ato de configurar a mesma história, numa mesma situação de comunicação (CARELLI et al., 2013). 
no campo da linguística aplicada à prática médica que Hydén e o próprio Mishler abrigaram sob o rótulo "Linguagem e Medicina" (HYDÉN; MISHLER, 1999). Para eles, a divisão proposta entre "falar ao paciente", "falar com o paciente", "falar sobre o paciente" e "falar pelo paciente" poderia mostrar os diferentes estágios de evolução de cada esfera comunicacional envolvida no processo, bem como os diferentes grupos de profissionais que predominam em cada uma, ressaltando a "diversidade de perspectivas teóricas e de pesquisa" (HYDÉN; MISHLER, 1999, p. 185). Mas, submeter o que temos considerado como núcleo duro da prática médica - o encontro clínico - à exclusividade de uma análise linguística é ainda declaradamente insuficiente se lembrarmos que a ciência biomédica é quem o legitima. Uma utopia teórica da comunicação em saúde teria que, para atender tais demandas, dar conta de todas as aporias e contingências da linguagem que, como vimos acima, o encontro clínico proporciona e, além disso, acomodar a potência colossal representada pelo discurso científico na sociedade moderna. Não basta, portanto, apenas analisar sob o ponto de vista linguístico os discursos produzidos nesse contexto ou adestrar profissionais da saúde por meio das humanidades médicas para celebrar histórias narradas nem, muito menos, ignorar as conquistas biomédicas jamais sequer sonhadas com que convivemos atualmente. Longe disso, é preciso antes um fio condutor que as organize e permita a ordenação do intrincado campo teórico constituído pelo encontro intersubjetivo no contexto do binômio saúde-doença.

Porém, que tipo de matriz conceitual permitiria a criação de uma base para a análise, não apenas da linguagem, mas das próprias condições de possibilidade do encontro clínico contemplando as relações tecnocientíficas, socioculturais, psicológicas e éticas de ambos os lados da mesa do consultório? Como unir campos tão distintos do conhecimento humano compactados e compartimentados no fatídico encontro? Segundo Ruth Cronje, o desafio contemporâneo da comunidade médica é encontrar paradigmas de racionalidade que dotem informações vitais não-quantificáveis (poderíamos dizer subjetivas) com uma força racionalizante capaz de guiar ações (CRONJE, 2003, p.160). O conhecimento clínico é voltado ao fazer e o fazer na medicina, é sempre o fazer em/com alguém e não em/ com algo e, por essa razão, não pode haver espaço para o dogma e a arbitrariedade. Entretanto, utilizar a ciência biomédica como único guia das ações clínicas é abrir mão perigosamente da dimensão ética envolvida no processo, dado que ao fazê-lo, sempre estaremos vinculados à relação sujeito (cognoscente) - obje- 
to (conhecido), em detrimento a uma relação intersubjetiva, moralmente mais adequada. Buscar alternativas "humanas" no interior da própria ciência, como vimos, não é legítimo. Tais questões nos remetem inexoravelmente às relações entre epistemologia e ética que estão, desde sempre, no âmago da medicina, mas que não são, de modo algum, privilégios dela.

\section{A Linguagem da Ética}

De fato, foi a articulação entre epistemologia (ou teoria do conhecimento) e ética (intersubjetividade) o ponto de partida de uma contundente metacrítica movida por três filósofos alemães à monumental filosofia crítica de Kant. Johann Hamann (1730 - 1788), Johann Herder (1744 - 1830) e Wilhelm von Humboldt (1767 - 1835) se posicionaram contra o papel reservado à linguagem pela filosofia da consciência, qual seja, o de simples mediadora na relação sujeito-objeto. Vista dessa forma, a linguagem não passa de mero instrumento de expressão de pensamentos pré-linguísticos. Para a tradição iniciada por eles, e que posteriormente receberia o nome de Tradição Hamann-Herder-Humbold ${ }^{15}$, a linguagem é essencialmente pensamento e tem, ela própria, um status duplo, tanto empírico, como transcendental. Por isso, ela pode reivindicar um papel constitutivo da razão não sendo mais necessário relegá-lo à consciência ou ao sujeito transcendental. Ora, se abandonamos a razão kantiana ao "tiroteio" da "pluralidade das línguas naturais", já não será mais possível garantir sua unidade "da mesma forma que o ponto de vista extramundano de um sujeito transcendental o faria" (LAFONT, 1999, p. 3). Em outras palavras, a razão destranscendentaliza-se na inapreensível fluidez da linguagem. Esse pensamento entrou para história das ideias com o nome de virada linguística.

A análise de Humboldt, mais sofisticada e profunda, identifica duas funções na linguagem que importam ao presente argumento. Por um lado, temos a dimensão cognitivo-semântica que:

[...] consiste em ver a linguagem não como mero sistema de signos, não como algo objetivável (intramundanamente), mas como algo constitutivo da atividade

15 Nome cunhado por Charles Taylor (LAFONT, 1999, p. X). 
do pensar, como a real condição de possibilidade dessa atividade. A linguagem é, assim, elevada a um status quase transcendental que se posta contra a subjetividade da autoria das operações que constituem a cosmovisão do sujeito. Com essa transferência de poderes, a análise da linguagem torna-se indissoluvelmente ligada à questão das condições de possibilidade da objetividade da experiência. Tais condições, a partir de agora, devem ser derivadas da função de desvelamento do mundo ${ }^{16}$ da linguagem. (LAFONT, 1999, p.18).

A dimensão cognitivo-semântica leva em consideração o fato de que a linguagem cria algo novo que não poderia existir de outro modo. E o faz por meio de um processo sintético - Humboldt chama de "articulação" - que consiste em, a partir do dimensionamento de um objeto no pensamento, combiná-lo com palavras, conceitos e descrições pré-estruturados pela linguagem, de modo que sua representação (transcendental) desapareça, fazendo surgir uma nova objetividade real (empírica) sem que, com isso, seja necessário suprimir a subjetividade. Nas palavras do próprio Humboldt, "apenas a linguagem pode fazer isso; e sem esta transformação [...] o ato de formação de conceitos, e com ele todo o pensar verdadeiro, é impossível" (LAFONT, 1999, p. 20). Dessa forma, independentemente da função de comunicação entre os seres humanos, a atividade discursiva é uma condição necessária para o pensamento. A articulação proposta por Humboldt antecipa a crítica ao paradigma da consciência na filosofia, em geral, e na linguística, em particular, influenciando pensadores que vão de Peirce a Saussure e de Frege a Wittgenstein, além do próprio Heidegger, com importantes desdobramentos.

A segunda dimensão da linguagem apontada por Humboldt é a comunicativa-pragmática, que consiste no

\footnotetext{
16 A autora utiliza o termo world-disclosing e atribui tal propriedade à linguagem devido à sua peculiar capacidade, diferente de outros sistemas de sinais, em não apenas designar objetos, mas também, classificá-los, ou seja, associar diferentes objetos a um mesmo termo e termos diferentes aos objetos (predicação). É por isso que a linguagem permite uma interpretação (conhecimento) geral do mundo (LAFONT, 1999, p. XII).
} 
[...] caráter constitutivo da linguagem como resultado de um processo ou atividade: a saber, a práxis do discurso. Nesse sentido, a linguagem torna-se a promotora da intersubjetividade da comunicação, condição de possibilidade do entendimento entre os falantes (LAFONT, 1999, p. 18).

Nesse sentido, Humboldt antecipa uma visão constitutiva da linguagem que só muitas décadas depois seria incorporada às discussões filosóficas por nomes como Mead, o segundo Wittgenstein, Gadamer, Habermas, Taylor e Benveniste, entre outros. Para demonstrar essa atividade, Humboldt faz uso de uma análise dos pronomes pessoais que se aproxima de ideias propostas por Émile Benveniste, Jean-Paul Sartre e Emmanuel Lévinas, como mostra o excerto de "Uber den Dualis" abaixo:

Por isso, a palavra deve ganhar sua essência no ouvinte e no falante. Este fato arquetípico de todas as línguas é expresso por intermédio da distinção entre os pronomes da segunda e terceira pessoas. Eu e ele são igualmente distintos e tão logo um deles seja pensado, tornam-se necessariamente objetos mutuamente exclusivos que exaurem tudo aquilo que nomeiam, em outras palavras, [esgotam o mundo em um] eu e um não-eu [restante]. 0 tu, por outro lado, nomeia um ele que se defronta com o eu. Enquanto eu e ele são cada qual baseado respectivamente na percepção interna e externa, encontramos no tu a espontaneidade de uma escolha. De fato, [o tu] é também um não-eu, embora não - como o ele - na esfera de todos os entes, mas de modo diferente, a saber, no modo onde a influência mútua resulta em ação comum. Por isso, o ele não consiste apenas em um não$e u$, mas igualmente em um não-tu; e é, assim, não só oposto a um deles mas a ambos. $\mathrm{O}$ fato de que a mesma forma pronominal possa ser encontrada em todas as línguas revela que os povos reconhecem que o discurso, em sua mais íntima essência, pressupõe que o falante ele mesmo distingua quem é o alvo de sua fala entre os outros que estão em sua presença (in LAFONT, 1999, p. 47).

Humboldt extrai desse argumento o fato de que a relação sujeito-sujeito é anterior à sujeito-objeto. "Uma vez que o processo comunicativo é tomado como estrutura referencial", afirma Lafont, "nem sujeito nem objeto podem ser constituídos em sua especificidade por mera contraposição de um ao outro" (LAFONT, 1999, p. 47). Não é possível constituir uma primeira pessoa por simples confron- 
tação com uma terceira. Ao contrapor um eu a um ele - em meio a outros entes do mundo objetivo - teremos apenas dois objetos opostos e nenhum sujeito constituído. $\mathrm{O}$ eu só será constituído na presença de um tu: o ele a quem o eu se dirige. É a atividade social que permite a diferenciação entre a primeira e a segunda pessoas por intermédio do discurso. Por isso, a linguagem individualiza e socializa ao mesmo tempo. Além disso, uma vez que a relação sujeito-sujeito é produzida com a contraposição da primeira e segunda pessoas, o papel da terceira é modificado: o ele deixa de ser apenas um não-eu, e passa também a ser um não-tu, oposto aos dois. "Apenas ao ser alçada à posição de objeto comum às duas primeiras pessoas, a terceira adquire seu [verdadeiro] status de objeto" (LAFONT, 1999, p. 48). Isso porque se a perspectiva eu-tu constitui a esfera de influência mútua que resulta em ação comum, a eu/tu-ele constitui a esfera de todos os entes, o conjunto de tudo sobre o que se pode produzir discursos e conhecer. Humboldt chega a afirmar que só por intermédio da abstração da relação sujeito-sujeito é que a relação sujeito-objeto pôde tornar-se paradigmática como teoria do conhecimento. A radicalização da Tradição Hamann-Herder-Humboldt encontra ecos na abordagem linguística presente na hermenêutica filosófica, em especial nas obras de Martin Heidegger e Hans-Georg Gadamer, com atenção particular à sua vertente cognitiva. A vertente comunicacional, intersubjetiva e ética só seria retomada mais tarde por filósofos como Jürgen Habermas, Karl-Otto Apel, Richard Rorty, Axel Honneth e Emmanuel Lévinas, entre outros.

\section{A Ética da Linguagem}

Há, portanto, uma ligação ancestral entre conhecimento e ética que, se por um lado, não é exclusiva da medicina, por outro, talvez tenha nela sua exposição mais sensível. Isso porque a medicina, graças à relação orgânica que guarda com a ciência que embasa sua prática, é especialmente suscetível ao sequestro de suas decisões mais delicadas pelo pólo do "conhecimento", o que se dá tanto na esfera individual, o encontro clínico propriamente dito, como nas esferas institucionais e/ou sociais. Tal procedimento sobrescreve o pólo da "ética" sendo responsável por grande parte do esgotamento das relações entre profissionais da saúde e pacientes que temos assistido atualmente. A opção por fundamen- 
tarmos na análise da linguagem a ligação entre conhecimento científico e ética da ação, no âmbito da prática médica, vem de encontro ao movimento descrito acima em que disciplinas denominadas humanidades médicas buscam resgatar o pólo da "ética" na referida relação, por meio do estímulo a narrativas ou, por exemplo, pelo uso instrumental da literatura. Entretanto, tal fundamentação faz surgir dois aspectos que modificam radicalmente a construção desse raciocínio, distanciando-o daquela proposta por esse tipo de abordagem. O primeiro é a percepção de que a ação ética só se dá no fluxo da linguagem. O saber ético é um saber prático (phrónesis) e o sujeito ético (phrônimos) se instaura, na e pela linguagem através da relação $e u-t u^{17}$. O segundo, decorrente da afirmação humboldtiana de que a relação sujeito-sujeito é primordial à relação sujeito-objeto, é que se possibilita, pela via da linguagem, agregar uma vertente epistêmica de raiz moral à relação intersubjetiva do encontro clínico. A resposta da pergunta feita acima, a propósito dos casos apresentados, sobre que tipo de operador poderia conectar uma palavra a um diagnóstico reside, então, na descoberta de que a linguagem, como híbrido empírico-transcendental, arquiessência do humano, é a única capaz de unir conhecimento teórico e comportamento moral a partir de um sistema "pré-conceitual", intuitivo e habitual, moldado por centenas de milhares de anos de evolução dessa espécie, conhecido simplesmente como interação humana, cuja somatória, em escala planetária, pode ser chamada de humanidade. Trata-se, portanto, de enfrentar o desafio proposto por Ruth Cronje, citado acima, (CRONJE, 2003) procurando especificamente por linhas de pensamento que sejam estruturadas, ou como teorias cognitivas da linguagem que desaguam em uma ética, ou, contrariamente, como filosofias que, a partir da interação ética entre indivíduos e de uma matriz linguística dela derivada, compõem uma teoria do conhecimento. As primeiras devem sustentar que a ideia de moralidade surge - e é mantida - pelo diálogo entre as partes envolvidas. As últimas devem demonstrar que a moralidade emerge primordialmente a partir da apreensão ética do outro, e só então, surge o diálogo.

\footnotetext{
17 Nesse sentido, adotamos uma posição para além da dicotomia principialista ou narrativista (v. nota 9) e nos aproximamos de uma visão prática da ética, como proposta por SVENAEUS, 2003 na afirmação: "A ética médica não pode ser apenas 'epistêmica'; deve também ser 'phronética', questionando substancialmente as próprias condições de possibilidade da profissão de bioeticista teórico". Para Svenaeus, não haveria bioéticos, mas pessoas agindo bioeticamente, à semelhança da medicina.
} 
O exemplo mais bem acabado da primeira é a Teoria do Agir Comunicativo de Jürgen Habermas (HABERMAS, [1981] 2012); o arquétipo da segunda é a filosofia da alteridade de Emmanuel Lévinas (LÉVINAS, 1980; WYSCHOGROD, [1993] 2005). Uma exploração do trabalho desses dois filósofos está muito além da proposta deste ensaio de modo que apenas algumas particularidades entre as duas obras serão traçadas aqui com vistas ao argumento proposto. Em primeiro lugar, ambas já possuem interfaces com a medicina (ver, por exemplo, AYRES, 2001, no caso de Habermas, e CLIFTON-SODERSTROM, 2003 e IRVINE, 2005, no caso de Lévinas, entre muitos outros). Da mesma forma, Habermas e Lévinas partem do mesmo pressuposto de que a linguagem tem uma dupla articulação caracterizada (i) pela emissão de um conteúdo (ramo semântico) e (ii) pelo fato de que este conteúdo é repassado a alguém (ramo pragmático). Habermas chama (i) de conteúdo locucionário e (ii) de força ilocucionária por sua capacidade de provocar reações nos interlocutores ${ }^{18}$. Lévinas, por sua vez, atribui à propriedade (i) o termo Dito (le Dit) e denomina (ii) Dizer (le Dire). Para ambos, falar é dizer algo a alguém; "e esta direcionalidade, esta tensão interpessoal que traduz minhas palavras a um destinatário, implica uma 'lógica' específica”, lógica esta, irredutível à relação sujeito-objeto (ROJAS, 2000, p. 40). Apesar dos pressupostos dos dois autores aproximarem-se no que Arne Vetlesen (VETLESEN, 1997) chamou de imanência normativa ${ }^{19}$ suscitada pela presença do outro, as semelhanças ficam por aqui. Habermas situa, por exemplo, o ponto de vista moral na primeira pessoa do plural, nós. Lévinas quase exclusivamente foca no "Outro" (ou o tu - mas não no sentido que Martin Buber dá ao termo), incorporado na metáfora da Face (VETLESEN, 1997, p. 2) 20. Um outro exemplo de diametral divergência é o tratamento que cada um dos autores dá ao conceito de sinceridade. Para Habermas, a ação comunicativa tem quatro pretensões de validade, a saber, inteligibilidade, verdade, sinceridade e correção normativa. Segundo Rojas (ROJAS, 2000, p. 57), a sinceridade, das quatro, é a que está mais distante de uma

18 A partir dos trabalhos de John Austin e John Searle. Cf. CAMPISI, 2005.

19 Trata-se da ideia de que a "normatividade nos é imanente dado que habita a própria estrutura da intersubjetividade humana. Meu ser-com um Outro já me coloca em uma relação ética, ou seja, uma relação que toca o Outro como vulnerável (Habermas) e a mim mesmo como responsável (Lévinas)" (VETLESE, 1997, p. 9).

20 Nesse sentido, Lévinas, em sintonia com Franz Rosenzweig e com o próprio Humboldt, entende que o nós não é um conjunto de eus e que o cuidado necessário para sua formalização não o qualifica como base para ética. 
proposta cognitiva já que não apresenta desempenho discursivo, nem racional, não sendo possível demonstrá-la argumentativamente (ao nível do conteúdo locucionário ou do Dito, portanto). Para Lévinas, entretanto, sinceridade não é apenas a concordância entre palavras e ações. Ela incorpora a exposição inescapável de nosso ser ao Outro. Se para Habermas, a sinceridade é entendida como atributo gnoseológico do Dito e a ele é submetida, para Lévinas, "a sinceridade é um Dizer sem Dito, um falar sem dizer nada (...) o reconhecimento de uma dívida, da não-indiferença do Outro" (ROJAS, 2000, p. 44). Com o diálogo em curso, a pluralidade dos interlocutores deixa mais clara a diferença entre os dois. Cito Pedro Rojas:

Enquanto que para Habermas, a alteridade não é radical, desde que já vem, em princípio, englobada na unidade da razão comunicativa e dialógica, para Lévinas, ao contrário, a alteridade do outro não é redutível, nem é a linguagem o caminho para sua anulação na unidade consensual de todos com todos (ROJAS, 2000, p. 45)

Para Lévinas, a alteridade não pode se dissolver no consenso. Segundo ele, a diferença e as assimetrias dela decorrentes são a própria condição da relação ética. Em Habermas, o consenso é o próprio télos da linguagem porque seu projeto é eminentemente ético e político (CAMPISI, 2005, III, p. 106). Lévinas, por outro lado, ao afirmar a ética como filosofia primeira, reforça a ideia de que o Dizer ultrapassa o senso comum da linguagem já que é a forma pela qual nos dirigimos ao Outro, nos tornando responsáveis pelo Outro e reivindicando sua resposta; o Dito é a linguagem como relação da palavra com o ente (WYSCHOGROD, 2002). O Dizer é "simplesmente a exposição que somos, a abertura exposta que me abre ao Outro e me torna responsável por ele sem poder negar a não-indiferença que a ele me inclina" (ROJAS, 2000, p. 44). É uma condição primordial, anterior e muito mais básica que qualquer entendimento.

Há motivos para acreditar que a filosofia de Lévinas "corrige", como diz Joseph Campisi, a Teoria do Agir Comunicativo de Habermas, em alguns de seus pontos mais intrincados (CAMPISI, 2005). Na mesma linha de raciocínio, Rojas argumenta que, em determinadas situações, nada impede que a ação comunicativa possa ser sequestrada pela razão instrumental teleológica renunciando, portanto, a seu leitmotiv (ROJAS, 2000, p. 50). É interessante notar que a literatura que relaciona Habermas com a medicina versa basicamente sobre os aspectos 
sociológicos e antropológicos da prática médica ${ }^{21}$. Já os artigos que tratam da interação da filosofia levinasiana com a medicina são, em geral, de teor fundamentalmente ético ${ }^{22}$. Isso talvez se deva à própria apresentação prima facie das respectivas filosofias, contudo, parece bem mais interessante, no caso da prática médica, fazer o caminho inverso. Pela via da linguagem, explorar os aspectos éticos da filosofia de Habermas e cognitivos da filosofia de Lévinas em suas múltiplas articulações com a medicina. Sem dúvida, muito há ainda a ser explorado numa leitura desses dois vastos autores - e de outros mais na mesma linha de pensamento ${ }^{23}$ - usando como guia a intersubjetividade idealmente ética do encontro clínico proporcionada pelo universo linguístico.

\section{Considerações Finais}

Pretendeu-se mostrar nesse ensaio que a abordagem narrativista do estudo da linguagem envolvida no encontro clínico, tal como vem sendo proposta, é insuficiente para dar conta da multiplicidade de seus aspectos, incluindo aqueles denominados bioéticos, razão de sua existência. Além disso, ao propor um esforço conjunto em direção a uma Teoria da comunicação em saúde de base ética, tendo como pano de fundo obras de Jürgen Habermas e Emmanuel Lévinas, ambicionou-se a construção de um campo do conhecimento e da ação capaz, ao menos, de equilibrar-se frente ao discurso científico atualmente hegemônico e, assim, nivelar as tomadas de decisão por parte dos profissionais de saúde em suas dimensões tecnocientíficas e ético-morais.

21 À exceção dos já citados artigos do médico e professor José Ricardo Ayres (Ayres, 2001, 2005, 2007), que o faz, entretanto, tendo como horizonte as práticas de saúde coletiva.

22 E, finalmente, os artigos que comparam os dois autores o fazem sob o ponto de vista acadêmico filosófico, geralmente de difícil extrapolação ao campo prático que a análise aqui empreendida exigiria.

23 Jacques Derrida, como crítico e amigo de Lévinas, Fredrik Svenaeus e Axel Honneth, apresenta leituras subsequentes e importantes a uma agenda como essa. No Brasil, o trabalho de Vladimir Safatle com a clínica lacaniana tem vários pontos de contato com nosso argumento. 


\section{Referências}

ATKINSON, P. Illness Narratives Revisited: The Failure of Narrative Reductionism. Sociological Research Online, v. 14, n. 5, p. 1-10, 2009.

ATKINSON, P. The discourse of medicine. Elliot G. Mishler, Norwood, N.J.: Ablex. 1984 xii + 211 pp. ISBN 0-89391-276-X and 0-89391-277-8 (pbk). Culture, Medicine and Psychiatry, v. 12, n. 2, p. 249-256, 1988.

AYRES JRCM. Sujeito, intersubjetividade e práticas de saúde. Ciência \& Saúde Coletiva; 2001 Jan;6(1):63-72.

AYRES JRCM. Hermenêutica e humanização das práticas de saúde. Ciência \& Saúde Coletiva. 2005;10(3):549-60.

AYRES, JRCM. A hermeneutical concept of health. Physis Revista de Saúde Coletiva, v. 17, n. 1, p. 43-62, 2007.

BISHOP, J. P. Rejecting Medical Humanism: Medical Humanities and the Metaphysics of Medicine. Journal of Medical Humanities, v. 29, n. 1, p. 15-25, 5 dez. 2007.

BRODY, H. Stories of sickness. $2^{\text {nd }}$ ed. New York: Oxford University Press, 2003.

CAMPISI, J. The Morals of Language: Habermas, Levinas \& Discourse Ethics. Dissertation Presented to the Faculty of the Department of Philosophy McAnulty College and Graduate School of Liberal Arts, Duquesne University in partial fulfillment of the requirements for the degree of Doctor of Philosophy. February 19, 2005.

CANGUILHEM, G. O normal e o patológico. 3.ed. Trad. Maria Thereza Redig de Carvalho Barrocas e Luiz Octavio Ferreira Barreto Leite. Rio de Janeiro: Forense Universitária, 2003 (Coleção Campo Teórico).

CARELLI, F. B. et al. Hidra de duas cabeças: Configuração ricoeuriana e narrador impuro numa narrativa do HC-FMUSP. Revista Internacional de Humanidades Médicas, v. 2, n. 2, p. 15-38, 2013.

CARELLI, F. B.; POMPILIO, C. E. O silêncio dos inocentes: por um estudo narrativo da prática médica. Interface - Comunicação, Saúde, Educação, v. 17, n. 46, p. 677-681, 2013.

CHARON, R. Narrative medicine: honoring the stories of illness. New York: Oxford University Press, 2006.

CHARON, R. The patient-physician relationship. Narrative medicine: a model for empathy, reflection, profession, and trust. JAMA: The Journal of the American Medical Association, v. 286, n. 15, p. 1897-1902, 17 out. 2001.

CHARON, Rita; WYER, Peter; NEBM WORKING GROUP. Narrative evidence based medicine. Lancet, 26 jan. 2008. v. 371, n. 9609, p. 296-297.

CLIFTON-SODERSTROM M. Levinas and the patient as other: the ethical foundation of medicine. Vol. 28, The Journal of medicine and philosophy. p. 447-460, 2003 
CRONJE, R.; FULLAN, A. Evidence-based medicine: toward a new definition of rational medicine. Health, 2003.

ENGEL, G. L. The need for a new medical model: a challenge for biomedicine. Science (New York, N.Y.), v. 196, n. 4286, p. 129-136, 8 abr. 1977.

FOUCAULT M. As palavras e as coisas: uma arqueologia das ciências humanas. 8a ed. Trad. Satma Tannus Muchail. São Paulo: Martins Fontes, 1999.

GADAMER, H.-G. The Enigma of Health. Stanford: Stanford University Press, 1996.

GREENHALGH, T. Narrative based medicine: narrative based medicine in an evidence based world. BMJ (Clinical research ed), v. 318, n. 7179, p. 323-325, 30 jan. 1999.

GREENHALGH, T. et al. Evidence based medicine: a movement in crisis? BMJ (Clinical research ed), v. 348, n. jun13 4, p. g3725-g3725, 2014

GREENHALGH, T.; HURWITZ, B. Narrative based medicine - Why study narrative? British medical journal, v. 318, n. 7175, p. 48-50, 1999.

GREENHALGH, T.; HURWITZ, B. Narrative based medicine: dialogue and discourse in clinical practice. London: BMJ Books, 1998.

GUYATT, G. H. Rebuttal From Dr. Guyatt et al. Chest, v. 133, n. 5, p. 1074-2, 1 maio 2008. HABERMAS J. Técnica e Ciência como "Ideologia". Lisboa: Edições 70, 2006.

HABERMAS J. Teoria do Agir Comunicativo I. Racionalidade da ação e racionalização social. Tradução Paulo Astor Soethe. São Paulo: WMF Martins Fontes, 2012.

HAYNES, RB. What kind of evidence is it that Evidence-Based Medicine advocates want health care providers and consumers to pay attention to? BMC Health Services Research, v. 2, n. 1, p. 3, 6 mar. 2002.

HURWITZ, B.; CHARON, R. A narrative future for health care. The Lancet, v. 381, n. 9881, p. 1886-1887, jun. 2013.

HYDÉN, LC.; MISHLER, E G. Language e Medicine. Annual Review of Applied Linguistics, v. 19, p. 174-192, 1999.

IRVINE C. The Other Side of Silence: Levinas, Medicine, and Literature. Literature and Medicine. The Johns Hopkins University Press; 2005;24(1):8-18.

KLEINMAN, A. The illness narratives. New York: Basic Books, 1988.

LAFONT C. The Linguistic Turn in Hermeneutic Philosophy. Trad. Jose Medina. Boston: The MIT Press, 1999.

LÉVINAS, E. Totalidade e infinito. Trad. José Pinto Ribeiro. Lisboa: Edições 70, 1980.

MACINTYRE, A. After Virtue. $3^{\text {rd }}$ Ed. Notre Dame: University of Notre Dame Press, 2007.

MCCARTHY, J. Principlism or narrative ethics: must we choose between them? Medical humanities, v. 29, n. 2, p. 65-71, 1 dez. 2003.

MEISEL, Z. F.; KARLAWISH, J. Narrative vs evidence-based medicine--and, not or. JAMA: The Journal of the American Medical Association, v. 306, n. 18, p. 2022-2023, 9 nov. 2011. 
MISHLER, E. G. The Discourse of Medicine Dialectics of Medical Interviews. [S.I.]: Greenwood Publishing Group, 1984.

MISHLER, E. G. The struggle between the voice of medicine and the voice of the lifeworld. In: CONRAD, P.; KERN, R. (Ed.). The Sociology of Health and IIIness: Critical Perspectives. New York: [s.n.], 1990. p. 295-307.

MISHLER EG. Patient stories, narratives of resistance and the ethics of humane care: a la recherche du temps perdu. Health: 2005 Oct 1;9(4):431-51.

PELLEGRINO, ED.; THOMASMA, DC. A philosophical basis of medical practice. Oxford University Press, USA, 1981.

POMPILIO, CE. As evidências em evidência. Diagnóstico\& Tratamento, v. 11, n. 1, p. 1617, 2006.

RATCLIFFE, M. Phenomenology, Neuroscience, and Intersubjectivity. In: DREYFUS, H. L.; WRATHALL, M. A. (Ed.). A Companion to Phenomenology and Existentialism. Oxford, UK: Blackwell Publishing Ltd, 2006. p. 329-345.

RICOEUR, P. Tempo e narrativa: a intriga e a narrativa histórica. Tradução Claudia Berliner. São Paulo: Tomo I. São Paulo: WMF Martins Fontes, 2010. v. 1.

ROJAS P. La ética del lenguaje: Habermas y Levinas. Revista de filosofía. p. 35-59, 2000.

SADEGH-ZADEH, K. Handbook of Analytic Philosophy of Medicine. Dordrecht: Springer Netherlands, 2015. v. 119.

SAFATLE, V. O que é uma normatividade vital? Saúde e doença a partir de Georges Canguilhem. scientiae studia, v. 9, n. 1, p. 11-27, 2011.

SAFATLE V. Grande Hotel Abismo: por uma reconstrução da teoria do reconhecimento. São Paulo: Editora WMF Martins Fontes; 2012.

SVENAEUS, F. The hermeneutics of medicine and the phenomenology of health: Steps towards a philosophy of medical practice. Dordrecht: Kluwer Academic, 2001. v. 5.

SVENAEUS F. Hermeneutics of medicine in the wake of Gadamer: the issue of phronesis. Theor Med Bioeth. 2003;24(5):407-31.

TOBIN, M. J. Counterpoint: evidence-based medicine lacks a sound scientific base. Chest, v. 133, n. 5, p. 1071-4- discussion 1074-7, maio 2008a.

TOBIN, M. J. Rebuttal From Dr. Tobin. Chest, v. 133, n. 5, p. 1076-2, 1 maio 2008b.

TOOMBS, S. K. Handbook of Phenomenology and Medicine. Springer Science \& Business Media, 2001.

VETLESEN AJ. Worlds apart? Habermas and Levinas. Philosophy Social Criticism. SAGE Publications; 1997 Jan 1;23(1):1-20.

WARSOP, A. The ill body and das Unheimliche (the Uncanny). The Journal of medicine and philosophy, v. 36, n. 5, p. 484-495, out. 2011.

WYSCHOGROD E. "Language and Alterity in the Thought of Levinas," in The Cambridge Companion to Levinas. Simon Critchley \& Robert Bernasconi, eds. Cambridge, UK: Cambridge University Press, 2002, pg 188-205. 
WYSCHOGROD E. From ethics to language. The imperative of the Other. Semiotica 97 (1/2) (1993): 163-76. in Emmanuel Levinas. Critical Assessments of Leading Philosophers. Volume I. Levinas, Phenomenology and His Critics. Edited by Claire Katz with Lara Trout. Routledge, 2005.

Submetido em: 09-12-2015 Aceito para publicação: 26-06-2016 